\title{
Credible as Evidence? Multilayered Audience Reception of Narrative Arguments
}

\author{
JARMILA BUBIKOVA-MOAN
}

School of Health Sciences

Kristiania University College

PO Box 1190 Sentrum

$N-0170$ Oslo

Norway

Jarmila.Bubikova-Moan@kristiania.no

\begin{abstract}
Building on a view of both narration and argumentation as dynamic concepts, this paper considers ways of assessing the credibility of narrative arguments constructed in empirical examples of conversational discourse. I argue that the key in any such exercise is to pay close attention to both structural and pragmatic details, particularly how conversational storytelling gets embedded in the surrounding discourse and how the way this is discursively accomplished vis-à-vis the narrators' multilayered audience may be reflective of their argumentative goals.
\end{abstract}

Résumé: S'appuyant sur une vision à la fois de la narration et de l'argumentation en tant que concepts dynamiques, cet article examine les moyens d'évaluer la crédibilité des arguments narratifs, construits dans des exemples empiriques de discours conversationnel. Je soutiens que la clé de tout exercice de ce type est de prêter une attention particulière aux détails structurels et pragmatiques, en particulier comment la narration conversationnelle est intégrée dans le discours environnant et comment la façon dont cela est accompli discursivement vis-à-vis du public multicouche des narrateurs peut refléter leurs objectifs argumentatifs.

Keywords: context, discourse analysis, evidence, narrative argument, narrative positioning, story credibility, story plausibility

\section{Introduction}

The topic of narration as argument has long attracted scholastic attention. Seeing storytelling as one of the basic communicative forms, Bennett $(1975,1978)$ suggested that it guides our judgements of situations and events in different settings. Several years later, while building on his earlier work, Fisher (1984, 1989) proposed seeing narration as a paradigm of human communication 
with its own attendant logic, "narrative rationality." Narrative was elevated to the master metaphor of human interaction with "homo narrans" - the storyteller - as its ambassador. The last two decades have witnessed a continued philosophical interest in the topic (Govier 2013; Govier and Ayers 2012; Kvernbekk 2003, 2013; Olmos 2013, 2015, 2017; Plumer 2011). As with the earlier scholastic debate (Fisher 1985, 1989; Rowland 1987; Warnick 1987), these more recent debates evidence scholars' differing views on a number of essential issues, including the very conceptual compatibility of narration and argumentation. Recently, Tindale (2017) suggested that a dynamic sense of argument is needed if the argumentative potential of narrative is to be recognized.

In parallel, a number of discourse analysts working in the sociolinguistic tradition (Bamberg and Georgakopoulou 2008; De Fina and Georgakopoulou 2012; Ochs and Capps 2001) have challenged the long-entrenched view of narratives as discursive events that follow a temporal ordering and a sequential structure (Labov 1972; Labov and Waletzky 1967). They have proposed alternative, dynamic models that more accurately capture how storytelling is woven into real-life interactional contexts and how it may serve as a platform for a discursive negotiation of social reality and identity positioning by speakers. While offering key insights on narration as talk-in-interaction and as a social practice (De Fina and Georgakopoulou 2012), with a few notable exceptions (Carranza 1998, 1999, 2015), sociolinguists have not thematized or explored the complex relationship between narration and argumentation in any depth.

Building on a view of both narration and argumentation as dynamic concepts, I will combine insights from argumentation theory and the sociolinguistic tradition within discourse analysis to explore the interweaving of argumentative and narrative discourse in the conversational context of research interviews and consider ways of adjudicating the credibility of narrative arguments emerging therein. As this paper will attempt to show, the complementary and convergent nature of these two strands of scholarship makes their combination both conceptually and analytically productive. Two empirical examples from qualitative research interviews with adult Polish migrants to Norway on their engagement in learning 
and using Norwegian as a second language (L2) will be used to illustrate my points. I will argue that in looking at story credibility in data of this kind, it is crucial to pay close attention to both structural and pragmatic details, particularly how conversational storytelling gets embedded in the surrounding discourse and how the way this is discursively accomplished vis-à-vis a multilayered audience, real and imagined, may be reflective of broader argumentative goals pursued by the narrator. ${ }^{1}$

In what follows, I will first ground this paper in theoretical insights on the potential connections and points of dialogue between narrative and argumentation theory, focusing particularly on Tindale's (2017) dynamic view of argument, Olmos's work on the argumentative assessment of story credibility (2013, 2015), and Bamberg's (2004) three-tier positioning framework for analyzing dynamic narrative activity. This will provide a conceptual and analytical platform against which the two selected empirical data excerpts will be interpreted. This again will lead to some concluding thoughts on the narrative-argumentative conundrum in general and assessments of story credibility for argumentative purposes in particular.

\section{Philosophical scholarship on narration as argument}

Are argumentation and narration two distinct discourse practices or do they overlap and have connections? If so, where, when, how, and how much? As already suggested above, over several decades, a number of studies within the field of argumentation theory have attempted to interrogate and unpack the "not-so-clear boundaries" between the two (Olmos 2013, p. 13).

One of the most comprehensive recent publications in English that provides insight into some of the key topics and debates in the field while advancing them further is the edited volume Narration as Argument (Olmos 2017). Particularly relevant to the present paper is Tindale's conceptual contribution (2017). Tindale argues that much existing work on narration as argument adopts a con-

\footnotetext{
${ }^{1}$ For simplicity, I will refer to the discourse participants who produce the narrative-argumentative discourse as narrators rather than arguers, narratorsarguers or arguers-narrators through most of the paper.
} 
ceptualization of argument as a product that is too static and narrow and sidelines the question of the process through which arguments get accomplished. He specifically discusses Kvernbekk's early work on the connection between narrative and argumentation $(2002,2003)$, where she considers the argumentative quality of explanatory narratives. As Tindale points out, there are two key points that her own argumentation revolves around. First, she underscores that narratives work by hindsight, whereby the conclusion is known to the narrator at the outset. Hence, the independence criterion of the premise and conclusion relation, integral to her conception of argument, is not met. Second, seeing story believability as a somewhat hazy concept, she admonishes that "believability tends towards the psychological" 2 and this in itself is not sufficient as arguments, in her view, should also be adjudicated on epistemic terms. Tindale also considers other scholarship, such as Govier's and Ayer's (Govier 2013; Govier and Ayers 2012), who explicitly warn against the epistemic risks involved in conflating argumentation and narration: "one can offer arguments through narratives and, in particular, through parables, but that doing so likely brings more risks than benefits, from an epistemic point of view" (Govier and Ayer 2012, p. 161).

On Tindale's (2017) reading, both conceptualizations privilege the structural perspective and thus provide no room to accommodate narrative as a potentially argumentative form of discourse. In line with his earlier scholastic work (Tindale 2015), he proposes a dynamic understanding of argument where the context in which it comes about plays a prominent role. He further argues that it is not only the structural (internal) features of an argument (i.e., the premise-conclusion link) but, crucially, also its reception by an audience that needs to be considered: "a dynamic sense of argument sees arguments as social events, personalized by those engaged in them" (p. 25). While he explicitly leaves the issue of criterial assessments of such dynamic arguments for another discussion (see his footnote 13, p. 25), he does briefly mention the need for audience-based criteria where a contextually appropriate

\footnotetext{
${ }^{2}$ Since pages in Kvernbekk (2002) are not numbered, the cited text cannot be page-referenced.
} 
set of questions would feature as key. Additionally, with reference to Plumer's (2011) and Olmos' (2013) work, he notes that stories need to have plausibility, or "a realistic plausibility" that concurs with the audiences' experience and offers "real world credence" (p. 26).

Clearly departing from Kvernbekk (2002, 2003), Govier (2013), and Govier and Ayers (2012) but, in crucial ways, aligning with Tindale's work discussed above, Olmos $(2013,2015)$ deals in detail with both conceptual issues regarding narration as argument and the assessment of their credibility.

In her 2013 article, Olmos draws on ancient and classical texts to discuss what this may entail. With recourse to the medieval philosopher Agricola, she too argues that not only a structural but also a pragmatic criterion of argument needs to be satisfied. In Agricola $^{3}$, the pragmatic criterion entails a "successive classification of different types of exposition with an increasing argumentation import," whereby he arrives "at a real gradual theory of argument" (Olmos 2013, p. 6). This proceeds from mere exposition of facts to argumentation through an intent to persuade (an audience). It is here that the importance of narrative plausibility comes in: given the presentation of the different pieces of an argument, including those in narrative form, will the audience be persuaded?

In her 2015 publication, Olmos takes this line of thought further and interrogates different criterial frameworks for evaluating story credibility, including, among others, Plumer's (2011), Fisher's (1989) and, once again, Agricola's. Given that these frameworks were conceived in different times and different scholastic traditions, her comprehensive treatment sheds light on the potential verisimilitude in assessing narratives as evidence in argumentative discourse. Building on and nuancing these frameworks, she proposes an integrative approach that features ten specific criteria arranged from inner (intra-diegetic) to outer (extra-diegetic) ones as follows (2015, p. 163):

\footnotetext{
${ }^{3}$ For information on the different editions of Agricola's text that Olmos (2013) refers to, see her footnote 16 .
} 
1. Internal plot or structural coherence

2. Internal characteriological coherence

3. Internal degree of detail

4. Story/storyteller coherence (arguer-related)

5. Coverage of relevant extra-diegetic evidence (material coherence) relative to argumentative practice involved

6. Uniqueness: situation of the story regarding other competing discourses

7. Independence: regarding other competing discourses (multiple-source confirmation)

8. Previous beliefs of audience relative to argumentative practice involved (audience-related)

9. External coherence/fidelity to the real world-narrative realism

10. Fidelity to human values: reliability and applicability of the story/degree of humanism

However, Olmos admonishes that the framework should not be seen as a definitive list of requirements that need to be fulfilled when assessing story credibility. She specifically notes that it could easily be extended and that incorporating rhetoric and pragmatic issues would amplify the framework's complexity.

Crucially, in both her 2013 and 2015 publications, Olmos also thematized the issue of different types of argumentative discourse that may have narrative qualities. Without aiming to provide an exhaustive list, she distinguishes between four broad categories (2015, pp. 156-57):

1. Arguments consisting of parallel, digressive storiesfictive or non-fictive stories presented as reasons for the acceptance of an otherwise independent thesis, such as arguments from example and analogy

2. Arguments with data in (partly) narrative form, such as narrative premises, including (but not restricted to) arguments from sacrifice or memory

3. Arguments about narratives (versions of events) - termed "core narratives," with claims and conclusions that may be partly narrative 
4. Pure narration - termed by Olmos "self-standing and selfreferring arguments"

While not explicitly framed as such and without specifically developing the concept of audience, this typology suggests a more nuanced conceptualisation of narrative arguments, with the various narrative types (or formats) assuming different argumentative functions.

Olmos also comments briefly on how the credibility of each argument type can be assessed. When it comes to the first two categories, she argues that the credibility of the narrative elements is essential for the interpretation and assessment of these arguments as a whole. In terms of the third argument type, Olmos suggests that although these are "usually not narrative-based arguments," (2015, p. 157) the very act of evaluating story credibility in these arguments is part of their analysis, understanding, and assessment. The fourth argument type is represented by narrative discourse that may not specifically put forward an argument. Yet, in relevant cases, its implicit veracity can be strengthened by a manifestly credible narration. ${ }^{4}$

Although Olmos' integrative criterial framework, as presented above, can clearly facilitate an understanding and evaluation of these argument types, some issues nonetheless continue to linger. For example, how will the framework work in practical application for highly dynamic discourse in everyday conversational contexts? Apart from criterion 8, explicitly thematizing the audience and thus in line with Tindale $(2015,2017)$, implicating it in assessing story credibility, how exactly are we to adjudicate the pragmatic/rhetorical aspects of narrative arguments, especially in argument types 1 and 2 that can be assumed to feature frequently in everyday conversations? Given the keen interest of recent discourse-analytical scholarship in dynamic narratives constructed in highly interactive, conversational contexts with multiple layers of audience, real and imagined, this represents a dimension where an interdisciplinary cross-fertilization with argumentation theory may

\footnotetext{
${ }^{4}$ Olmos (2020) offers further nuancing of this category and cautions that not every piece of pure narration can and should be assessed argumentatively.
} 
potentially be fruitful. How then does discourse-analytical literature deal with conceptual concerns, and how are the potential ties and links between narrative and argumentative discourse thematized there?

\section{Discourse-analytic scholarship on narration and argumenta- tion}

As with argument, there is much scholastic disagreement on how to conceptualize narrative. In discourse analysis and related disciplines, such as sociolinguistics, it is particularly the seminal work of Labov (1972) and Labov and Waltezky (1972; 1967) that long held definitional primacy. Seeing narratives as discursive events that follow a temporal ordering and a sequential structure, they identified six structural elements as being constitutive of a fullyfledged narrative:

1. Abstract — gives a summary of the story

2. Orientation-lays out the "whos," "whens," and "wheres" of the story

3. Complicating action-presents what has happened

4. Resolution-presents how the complicating action has been resolved

5. Evaluation - gives the point of view of the speaker

6. Coda-links the story to a current situation or effect of the story

While highly influential, this model has, in the last two decades, been critiqued for conceptualizing narrative as overtly static and, therefore, as inadequate to capture the multivocality and multiplicity of narrative activity that goes on in everyday discourse.

An alternative, highly influential framework that addresses this issue has been proposed by Ochs and Capps (2001). Much like Tindale (2017) in his work on dynamic conceptualisations of narrative arguments, they look beyond the story as a product and towards the process of storytelling in its contextual frame. The repertoire of narrative activity analytically pursued in this line of research has thus been redefined to include both the so-called 
"big" canonical "Labovian" stories as well as the so-called "small" stories produced in naturally occurring conversations and presented in a variety of narrative formats, such as hypothetical stories, story snippets, story fragments, and story deferrals (Georgakopoulou 2007). Compatible with this broadened conceptualization, Ochs and Capps (2001) consider narrative through several dimensional criteria that give it a distinctly dynamic character:

1. Tellership - who gets involved, how, and how much in the process of telling, varying from one to more than one narrator

2. Tellability — what constitutes a tellable story, ranging from highly tellable to having low tellability (e.g., degree of narrative detail)

3. Linearity-how the story is woven in time; whether it follows a closed chronological path or diverges from it in open and fluid ways

4. Contextual embeddedness - the degree to which storytelling is attached to the local context, discourse, and social activity

5. Moral stance - relates to Labovian evaluation but is conceptualized on a continuum from constant/static to fluid/dynamic

Aligned with Ochs and Capps (2001) and firmly grounded in social interactional approaches to narrative, Bamberg (1997) has proposed a three-tier positional framework that presents storytelling as a multi-dimensional interactional achievement involving multiple layers of potential narrative activity driven forward by different characters and, crucially, audiences. The core of the framework is to provide an analytical toolkit that aids in understanding how narrators position themselves in discourse vis-à-vis their audiences and how their audiences in turn position them. Bearing in mind that this nuanced conceptualization of storytelling contexts is profoundly multivocal, it proceeds from the close discursive level of the constructed story towards interactional and broader societal levels in which the story is embedded: 
Level 1: The story world—presents a particular theme or action driven by specific characters

Level 2: The interactional situation-provides the close contextual, real-world frame within which the story world is constructed

Level 3: The wider discursive context - relates to the broader societal context that frames the very act of storytelling and provides key structural indexicals that may be variably appropriated or resisted by the narrator/s and, arguably, by their audience/s.

On a conceptual level, Bamberg's multi-dimensional framework seems to map well onto Olmos' (2015) proposed integrative framework for assessing story credibility in that it too advances from the inner workings of discourse (inter-diegetic criteria) to its outer layers (extra-diegetic criteria). Bamberg's level 1 can be seen as corresponding to Olmos' criteria 1-3, level 2 as corresponding to criteria 4-7, and level 3 as corresponding to criteria 810 (Olmos 2020). Despite coming from different scholastic traditions, the frameworks can thus be seen as convergent, complementary, and also highly compatible.

What then does the discourse-analytical literature say about narrative as argument? While narrative accounts of experience have been framed as specifically argumentative resources referred to as exempla that powerfully illustrate the discursive negotiations of meaning (e.g., De Fina 2003), the complex relationship between narration and argumentation seems to be largely underdeveloped theoretically in this line of research.

An exception in this regard is Carranza's work (1998, 1999, 2015), which, with recourse to both narrative discourse analysis and argumentation theory, unpacks some of the theoretical complexity that the narrating-arguing mode may entail. She argues that different communicative contexts place different discursive demands on interactants participating in a dispute or a confrontation or presenting a claim on a potentially controversial issue. Her work interrogates the structural interweaving of narrating and arguing, not least how they may blend, intersect, and alternate and how narrators may draw on a multitude of discursive devices, such 
as direct speech, repetition, or negation, to present persuasive arguments or back up their local claims. Yet, she claims that "notwithstanding the potential for interrelations between them, in any single argumentative-narrative text, argumentativity and narrativity cannot be equally dominant" $(2015$, p. 73$)$. This then suggests that she sees the two as essentially distinct discursive modes that can be dissected as such.

Also important for the present discussion, her approach is explicitly grounded in a rhetorical view of argument where the concept of audience is key. Her conceptualization of audience is broad and includes both an implicit and actual audience. Interestingly, this also includes the concept of the third party that essentially comprises "socially shared values and interdiscursivity, corresponding to the circulating discourses in society" (2015, p. 61). In line with Bamberg's work, though not explicitly referenced as such, she thus discusses narrative argumentation in terms of the story-world and the interactional world and offers reflections on narrative plausibility within what essentially corresponds to Bamberg's third positioning level. She argues that "narrative plausibility, particularly concerning the world as we know it, derives from common sense" (2015, p. 63). This then also echoes Olmos' (2015) extra-diegetic criteria 10 (fidelity to human values), which she consciously builds on Fisher's narrative fidelity criterion (i.e., "does it provide a reliable guide to our beliefs, attitudes, values and actions?") while also nuancing it with Cicero's insights.

\section{Story credibility in selected empirical examples}

In the following, I will attempt to combine some of the theoretical insights presented above and use them as a lens through which to analyse and interpret empirical data. Taking as my vantage point Tindale's (2017) dynamic view of narrative argument where the concept of audience is key and a dynamic view of "a living narrative" (Ochs and Capps 2001) occasioned in specific contexts and thus situationally contingent, I will draw specifically on Bamberg's insights into speaker positioning in narrative discourse. Particular attention will be paid to how research interview participants employ various discursive devices to construct rhetorically 
persuasive narrative-argumentative discourse in which they actively engage with a multilayered audience, real and imagined, and how this may serve situationally conditioned argumentative ends. I will also draw on Olmos' (2015) integrative framework for assessing story credibility. However, rather than strictly applying or considering each and every criterion listed, a practice Olmos herself warns against, I will expand only on those deemed relevant vis-à-vis the nature of the available empirical examples (i.e., narrative-argumentative discourse constructed in research interviews). The following inter-related concerns will guide the analysis:

1. What is the narrative/story presented?

2. How is it embedded in the immediate discursive context, and, relatedly, is somebody in this context asking for reasons/justification?

3. Is the narrator presenting an argument (in the sense of offering a reason/s for something else)? If so:

a. What is the argument — what is the narrator's claim and what is/are the reason(s)?

b. Is/are the reason(s) and the claim(s) conveyed through the story?

4. How credible is the constructed narrative as argument vis-à-vis the narrator's multilayered audience?
a) Imagined/storied (story characters-Bamberg's Level 1)
b) Actual interactional (interview participants- Bamberg's Level 2)
c) Imagined (broad societal discourse/s-Bamberg's Level 3)

While the first three questions are meant to aid in unpacking the basic building blocks of the narrative-argumentative activity in each example, the fourth question concerns the main thrust of the analysis, namely a credibility assessment of the narrativeargumentative activity vis-à-vis its multilayered audience. However, while the questions suggest analytical discreetness, teasing out the narrative and argumentative features of each passage necessitates an iterative rather than a linear analytical approach in which 
the questions necessarily feed into each other as the subsequent analysis will make clear. I will use the cinematographic metaphor of zooming in and out of Bamberg's levels to underscore the subtle transitions between the inner workings of the story world and the outer layers of the interactional and wider socio-discursive contexts.

\subsection{Preliminary methodical notes on the empirical data}

The empirical data consists of two excerpts drawn from a corpus of 19 research interviews with adults of Polish ethno-linguistic heritage who have moved from Poland and settled in Norway with their families in recent years. They were collected in 2015 and 2016 as part of a discourse-analytic study on bilingual education policy in Norway (Bubikova-Moan, 2017a). I acted as the researcher-interviewer and used Polish with all my interview participants.

The selected excerpts relate to the overarching thematic category "narratives on second language learning." Data categorized under this theme provide rich grounds for exploring how the study participants construct their experiences with learning and using Norwegian as a second language (L2) while drawing on narrativeargumentative forms of discourse. The particular selection presented here is meant to illustrate the wealth of issues this potentially generates.

A detailed description, as well as an extensive analysis of the data set, has been presented elsewhere (Bubikova-Moan 2017a, $2017 \mathrm{~b}, 2019)$. It is nonetheless of special note here that the interview participants are primarily labour migrants to Norway and hence explicitly or implicitly implicated in the wider societal discourse on migration. Suffice it to say that in Norway, as in other national contexts, this discourse has in recent years become increasingly polarized and steeped in deeply divisive antiimmigrant, ultra-nationalist rhetoric (see e.g., Andersson 2012).

It is equally important to bear in mind that research interviews are a specific discursive practice that raises certain expectations as to the particular roles that interview participants are to adopt in the unfolding discourse, including the ordering of turns: the researcher-interviewer normally poses questions to the interviewee, and the 
interviewee normally acts on the assumption that they should answer the posed questions rather than posing their own.

\subsection{L2 learner as a parent}

The first excerpt is a conversation between the interviewer (Int) and a mother of four (M01) who, a few years prior to the interview, reunited in Norway with the family breadwinner-her husband and the children's father-after a prolonged period of him periodically commuting between a job in Norway and his family in Poland. ${ }^{5}$ On a broad thematic level, it presents a prominent leitmotiv in the data, namely the interviewees' frustration and difficulties with parenting preschoolers and school-goers without being able to communicate with the preschool and school authorities in L2 due to their self-reported, insufficient L2 fluency and confidence.

\footnotetext{
5 Note that both excerpts follow simplified, discourse-analytic transcription conventions, including capitalization. See Appendix 1 for further details. Note also that all translations from Polish into English are my own.
} 
01: Int: right, so what do you think? how is it to parent a bilingual child -

02: $\quad$ ehmm - a multilingual child?

03: M01: that's really fascinating and stressful @,

04: Int: oh, I see, why?

05: M01: because there was this funny situation when we came here and my Danny

06: who did not speak much he started preschool. in some two months Danny started to speak but in Norwegian! and I sat in a bathtub - we were having a bath of course and he tried to say to me what they did in preschool and he started to speak in Norwegian. and I started to cry. people say that kids speak the language of the mother. but in what language did he start to speak to me? in Norwegian! it was not my language. I could not speak it except for hi bye-bye -

Int: right! you did not understand him -

M01: nothing! nothing! I started to cry. Pete ((husband)) comes in and asks "what's wrong?"

and I say "Pete tell me what is my kid trying to say to me? (..)

help me Pete! what am I supposed to do?"

and then I said "no Pete I have to start a Norwegian course.

I have to be able to speak with my child.

I have to understand what my child is saying to me".

that was a very frustrating experience.

Int: and when you talked Polish to him ((son)) then he would -

M01: he would speak Norwegian! -

Int: always?

M01: he could not say anything ((in Polish)). but I - since I work in preschool I started to think about why it is so. If parents come with their child say at eight o'clock. they pick ((the child)) up at half four or if ((they come)) at seven and pick up at four (.) that means that some children are the entire day - poor little things - my children were never picked up that late - but nevertheless they spend most of their day in preschool! Int: right!

M01: and there they have contact with Norwegian. when they come home they talk. they may hear a bit of Polish. say when they go to bed ((she elaborates on her reasoning to conclude)) - it's not automatic that they speak their mother tongue. unfortunately that's not the case.

Int: how does that feel for you? Is it - at the beginning it wasn't easy -

M01: it was very frustrating. very stressful. It was also motivating in the sense that I have to take a Norwegian course. I have to understand my children. full stop!

((the mother goes on to confirm her position with further elaboration, unchallenged by the interviewer))

On reconstructing this passage with the aid of the first three analytical questions, we see that there is one main story (lines 5-21) that revolves around the mother's personal experience of talking to her son about his day in preschool while performing their personal hygiene routines. When it comes to the embedding of the story in its immediate conversational context, it is prompted by the interviewer's explicit demand for justification of a value judgement (line 4). However, deciding whether the narrator pursues explanatory or argumentative ends depends on how we relate the story to 
the rest of the discursive activity in the passage. Both the interactional and story dynamics are key here.

Zooming in to Bamberg's level 1, we see that the narrative itself revolves around a brief, yet emotionally charged conversation between three characters: the mother, her young son, and her husband. To enhance its urgency, drama, and rhetorical appeal, the narrator draws on a number of discursive devices, most importantly: 1) direct and indirect speech (line 8, lines 15-20), 2) inner speech (lines 10-12), 3) repetitions (line 14), 4) restatements (lines $16-17 ; 19-20)$, and 5) intimate visual details of the physical location of the narrative (bathroom/bathtub, line 7-8). Already in the story world, the mother engages an imagined, anonymous audience ("people," line 9) to voice a claim about migrant children's mother tongue competence. From a discourse-analytic perspective, this lends it a status of a generalized, communally shared knowledge which potentially sanctions her linguistic choice expectations. The fact that the son's response does not cohere with the suggested normative behaviour is central. The ensuing orchestration of the narrator's own voice in dialogue with the mostly narratively silent voice of her husband serves to dramatize the resolution of her dilemma, which she closes in a final restatement of her initial value claim (line 21). In Ochs' and Capp's (2001) terms, through its dramatic and rhetorical appeal, the story can be considered highly tellable in everyday conversational terms, even if it is brief and not elaborate in terms of plot. It follows a linear, sequential order, and while embedded in and clearly linked to the immediate discursive context, it is also fairly self-contained. The mother's evaluative (moral) stance remains stable and, thus, seemingly intra-diegetically coherent. In these ways, it seems to satisfy Olmos' criteria for structural and characteriological coherence as well as vividness (criteria 1, 2, 3).

Zooming out to the close interactional context (Bamberg's level 2) and bearing in mind the genre expectations, the excerpt presents a type of speaker positioning typically adopted in research interviews (Labov 1972; Wortham and Gadsden 2006): the mother engages in answering questions, while the researcher-interviewer alternates between posing questions (e.g., lines 1,3) and being mostly an attentive listener tuned into the situational context. As 
such, the story may initially be seen as simply the narrator's way of responding to the interviewer's bid for justification (line 4) and, hence, as the narrator's attempt at justifying a value claim by narrative means. However, as it unfolds, it acquires another layer, namely that of being a narrative self-explanation or an a posteriori rationalization of the narrator's motivation to learn Norwegian. In other words, the son's limited command of Polish and, relatedly, the mother's wish to communicate with her child are presented as legitimate reasons to engage in L2 learning. The interactional exchange between lines 22 and 24 is pivotal from a dialectical point of view; despite the fact that the story is constructed in interdiegetically plausible ways, the interviewer questions its credibility. Taken up as a bid for justification, this unleashes the argumentative potential of the narrative and turns it into a personal testimony regarding the child's limited bilingual competence. To strengthen its legitimacy, the mother offers another short narrative in her subsequent interactional moves (lines 25-35), presenting a generalized account of an average day in the life of a Norwegian preschooler. This second narrative analogy can be seen as supporting what would otherwise remain an isolated piece of personal, anecdotal evidence. Yet, since the interactional audience does not probe it, the argumentative potential of the passage is not further developed. Instead, facing the same evaluative request (line 36) she was already confronted with at the beginning of the passage, the mother restates her initial position, which also remains unchallenged. On this reading, then, we can conclude that both the narrator's claim as well as the reasons she provides to justify it are expressed narratively.

Bamberg's third positioning level is highly abstract and theoretically complex, as it calls on wider societal discourses voiced by heteroglossic, yet only imagined, audiences. While narrators may sometimes explicitly draw on these macro-discourses as their broader interpretative frames, often the analyst may need to resort to considering implicit textual cues that index their relevance in tacit ways only. ${ }^{6}$ In this very passage, for example, the mother

${ }^{6}$ On these issues, see the scholastic debates among several prominent discourse analysts representing, roughly speaking, the ranks of critical discourse analysts 
places her story chronologically only vaguely at the initial stage of their resettlement ("when we came here," line 5). Given that Norwegian discourse on migration underscores L2 learning as a key path to social, professional, and educational integration in a new society (Ministry of Children and Families 2012; Ministry of Education and Research 2019), the temporal marking is discursively salient in so far as it may justify her largely limited command of L2 in the eyes of her imagined as well as interactional audience. Relatedly, it enables her to position herself as a "good migrant" ready to put effort into learning L2 from early on. In fact, this would potentially lend her resolution more real-world credence (Olmos' criterion 9) than the actual claim put forward through her story world (level 1). As was also carefully hinted at by the interviewer in the interactional world (level 2), this very claim can be critically questioned. For example, with recourse to empirical research on children's bilingual development (Grosjean et al. 2013), it can potentially be explained as a temporary developmental phase, if not simply a situational whim or an attempt by the young child to tease his mother. To strengthen its credibility as more than just anecdotal evidence, the mother therefore draws on the broader discourse on family life in the Norwegian welfare state where the right to universal, full-time, and heavily subsidized kindergarten care functions as leverage for one of the welfare state's core pillars, namely that of a high degree of labour market participation across genders (Brochmann and Djuve 2013). By analogy, migrant children's limited time with their parents at home and, hence, their limited exposure to their home language is presented here as a plausible reason for their limited competence in it. While this justification is not further challenged by the interviewer, the lack of insistence on further elaboration should not be taken at face value as it is also necessarily conditioned by genre constraints as well as situational power dynamics. Indeed, any further probing could have been potentially face-threatening for the narrator.

(CDA) on the one hand and conversational analysts (CA) on the other (e.g., Billig 2016; Schegloff 1997; Wetherell 1998). 
In summary, we can argue that in everyday conversational terms, the passage displays inter-diegetic coherence. The story has a simple plot that is structurally coherent, as are the characters that feature therein. The narrator draws on a variety of discursive means to capture the intimate details of the situation, which, by implication, enhance its narrative vividness. Yet, despite these qualities, its extra-diegetic credibility is clearly open to doubt visà-vis several of Olmos' criteria. The brief questioning by the interactional audience signals that it remains unconvinced (criterion 8). This may be because, potentially at odds with the audience's expectations, the story cannot be ruled out as an isolated piece of anecdotal evidence only. This also makes it difficult to establish its real-world credence (criterion 9). Even when its extra-diegetic fidelity is potentially strengthened by the second analogical account and no further probing follows, the case is thereby not necessarily closed, especially when taking into account the mostly non-confrontational genre of research interviewing.

\subsection{L2 learner as a citizen in the new society}

In the following passage, the issue of learning and using Norwegian as L2 is also central. However, unlike in the first example, where the need for L2 competence is framed within the private bounds of the interviewee's home and related to parenting duties, here it is thematized explicitly as a skill that enables immigrants to function as citizens in the new society. The exchange involves three interactants - the interviewer (Int) as well as the mother (M07) and father (F07) in one of the interviewed families.

\footnotetext{
01: Int: so how is it for you to speak Norwegian?

02: M07: for me it's nice because -

03: F07: weird because -
}

((here both interviewees engage in detailing how they experience L2 learning, including the difficulty of learning a new language as adults, growing up in a specifically diglossic Polish setting and learning Russian as a first foreign language at school)) 
04: M07: $\quad$ well I'm a bit upset with myself that I still know too little ((Norwegian)). I'd like

05: to learn more but there is no time. I'd love to go to school. take

06:

a really good course or just a normal course because I've never

really done anything like that. well one either works or takes a course.

and when one works one is earning money and when one takes a course

one doesn't earn money.

F07: but there is one more thing.

well, it's really a question of their xenophobia. or I don't know -

Int: ehm. ehm. -

F07: tolerance or intolerance. there is definitely a big difference (...)

- when one goes anywhere. say to a public office or a shop

and one starts to speak in Norwegian. even if it's stilted -

because if you start in English -

M07: I remember how my husband sent me to set up a bank account for myself.

when I started to work I had to have an account.

I say «you will go with me to set up an account».

he says «no! you go alone!»

I say «no, not in a thousand years! such a serious thing

as setting up a bank account! I won't understand!».

and at that time my Norwegian was really not good.

it was real beginnings and he says «no. you go alone!». so I went.

there was this really lovely lady in the bank, in X ((name of bank))

and she asks me «and where are you from?

I say «well, from Poland»

and she says «but you Poles, you don't speak Norwegian!

and you are doing really well!».

and I say «really?»@ because there is this opinion about us -

Int: ehm, ehm. -

F07: but if I went with you then you'd always think

«and my husband needs to come along always because»-

and well now you know you can go not just there -

M07: yeah, only that I would like to defend Poles who don't speak Norwegian - daddy, peeing again -

(the mother points at their young son who appears in the doorway, clearly indicating that he needs help with going to the bathroom; the father leaves with him and the conversation is resumed between the interviewer and the mother)
37: Int:
right. so it was difficult at the beginning?
38: M07:
right, for sure, at the beginning yes! but it's a question of daring
39:
a bit too...

(the conversation continues on the theme of how it is to speak L2 at present with the mother providing several storied accounts from her workplace)

In this excerpt, the narrative-argumentative activity is structurally more complex than in the first. This is because we have more interactants (Bamberg's level 2) and, relatedly, different subordinate claims that are being put forward and that feed into each other in a swift succession of conversational turns.

Turning to the first three analytical questions, the passage revolves around the couple's L2 learning and use, prompted by the 
interviewer's request for an evaluation (line 1). This then provides the broader thematic context laid out in more detail in the subsequent lines (1-9). Already here, the couple signals a disagreement on the issue (lines 2 and 3). Embedded in this context, yet not explicitly interactionally prompted, the father then puts forward a claim (lines 11-16) that socially sanctioned linguistic choices (i.e., speaking Norwegian rather than English in public spaces) have to do with Norwegian xenophobia or intolerance. Drawing on a discourse with clear racial undertones (Bamberg's level 3), the father self-interrupts (line 11) and, upon the interviewer's brief acknowledgement of interactional in-tuning and attention, launches into what may seem as a storied justification of his claim. Zooming in to the level of the story world, he first draws on a generalized, anonymous character ("one," lines 14 and 15) who opts for Norwegian rather than English in conducting their everyday business in public spaces. Again, the pronominal choice lends it both more rhetorical and epistemic weight as a collective rather than purely personal experience. However, before providing any further details, he is interrupted by his wife (Bamberg's level 2) who offers a more elaborate story in the rest of the passage. So far then, we have a claim, articulated first only vaguely but becoming clearer as the father's short narrative starts to unfold. It is reasonable to assume that the unfolding narrative is meant to convey reasons for his claim.

The mother's story, on the other hand, revolves around her visit to the bank. The focus is now firmly on her emotional discomfort and lack of confidence in having to rely on her own L2 skills in a formal institutional context. Like the father's claim (lines 11 and 13-16), the story comes unprompted, and it is unclear at first why she launches into it and where she is heading. In fact, the multiple interruptions in the interactional context complicate a straightforward resolution. Thus, also in this case, we are left with several interpretative options. First, if we consider the mother's story as embedded in the father's account (i.e., lines 10-35), we can see it as an a fortiori argument (Olmos 2014, pp. 202-3) in narrative form on ethnic prejudice at a structural level (i.e., regardless of their L2 skill, migrants are being discriminated against in Norwegian society). In other words, the mother's story illustrates and 
reinforces the incomplete narrative argument of the father. If, however, we take into account the entire passage (i.e., lines 1-39), the mother's story can be seen as an analogy drawn between her own experience and the wider experience of Polish migrants to Norway feeling insecure using L2 in public contexts. Then, we can argue that the claim itself begins with a false start on line 30 and is completed on line 38. Despite being somewhat disjointed, we can assume it to be: "for the Polish migrant, it is a question of daring to speak rather than not being able to speak L2 in public spaces." On this reading, the story itself (lines 17-29) functions as a justification (reason) for the claim as it illustrates the operation of ethnic prejudice in practice. How credible then are the narrative arguments that are being put forward?

By zooming in to the level of the story world (Bamberg's level 1), we see that rather than utilizing an elaborate plot, the main story is driven forward by three different story characters: the mother, her husband, and a bank clerk. The voices of the characters are orchestrated as having several disagreements: there is one disagreement between the mother and her husband as to whether the former can manage an important institutional encounter in L2 on her own; the other, mostly oblique disagreement, or perhaps just a difference of opinion that may be situationally inappropriate to develop further, involves the mother and the bank clerk and concerns L2 proficiency among Polish migrants to Norway. Similar to the narrator in the first excerpt, the mother draws on a variety of discursive tools to enhance the story's persuasiveness, most notably: 1) direct speech in which the two short exchanges are orchestrated (lines 19-24; 26-30), 2) hyperbole ("not in a thousand years"-line 21), 3) adverbial amplification ("really"-lines 23, 25, 29), and 4) contrastive descriptions (lines 28 and 29). As a whole, her narration contains descriptive detail that adds to its vividness and, following Ochs and Capps, its tellability. While the interactional interruptions create a certain degree of fluidity and chronological disjunction, the narration nonetheless follows a fairly linear path and offers a clear moral stance. As a short conversational story, it may therefore be seen as inter-diegeticaly coherent (Olmos' criteria 1, 2, 3). 
Zooming out to the interactional context (Bamberg's level 2), the real-life audience consists of the interviewer and the father. The former once again aligns with the expectations of the genre and adopts a fairly passive stance as a listener throughout most of the passage, providing only a few brief confirmations of interactional attention (lines 12, 31). No critical or other questions are asked until line 37 , where rather than elaborating on the mother's interrupted chain of thought, the overarching theme of the passage (i.e., that of the couple's experience with L2 learning) is revisited. As an interrogative yes/no speech act, this then serves as a bid for a summary or a closure, which the mother accepts. The father, on the other hand, assumes a more active interactional involvement. First, he prompts the story with his own, albeit unfinished, narrative. Second, he interrupts the narration and elaborates on the orchestrated exchange in the story world where he himself features as a voice (lines 32-34). However, he does not challenge the credence of the narration as a whole. Rather, he only engages in backing up the position that he has been assigned there; through direct speech, he voices the mother's inner speech that affirms his moral stance in the storied world as legitimate. Resuming the interactional floor, the mother does not challenge this but affirms it briefly before she proceeds towards formulating her main claim. While the son cannot be considered an active audience in the exchange, his silent presence is nonetheless also salient interactionally as it brings to a halt what can be assumed to be the mother's unfolding narrative reasoning.

How then does the imagined audience on the third positioning level come in? As in example 1, the narration is also specifically placed at the initial stage of resettlement, a fact that is underscored several times by the mother herself (lines 23, 24, 38) but also the interviewer (line 37). Once again then, this provides a subtle, yet important contextualization cue in so far as it justifies the mother's limited command of L2 as well as her inner unrest and lack of confidence in having to use it in an institutional setting. This is, however, a minor point here. Most importantly, the mother explicitly draws on a wider discourse on Polish migration to Norway and argues against what she perceives as an ethnic stereotype. That the ethnic dimension is key in this passage gets backing through addi- 
tional cues: 1) multiple framing through explicit references to ethnic categories (Polish versus Norwegian); 2) assumed links between linguistic preferences and xenophobic attitudes grounded in ethnic membership (lines 11-16); and 3) lack of L2 command generalized to the Polish people as a group (lines 25-30). This echoes a divisive us-and-them discourse, increasingly salient also in the broader societal, political, and media contexts in Norway (Andersson 2012; Brochmann and Hagelund 2012). As such, we can argue that through her narrative argument, in which she resists the ethnic stereotype, she also clearly resists the voice of this very (imagined) audience. This applies regardless of whether we see it as an a fortiori argument or an argument by analogy.

We see that the couple's exchange also has clear gender undertones with the father being positioned as dictating the state of affairs and the mother aligning with the marginalized positioning he has assigned to her. It is, however, of note that this is so in this specific context, which necessarily raises expectations on what can and cannot be said. For example, further discursive resistance by the mother, or an orchestration of a more intense dispute between the couple on this very issue during the interview, could be considered highly situationally inappropriate. In fact, one may also argue that the mother's abrupt interruption of the father's racially motivated narrative on line $17 \mathrm{can}$, in fact, also represent a facesaving act vis-à-vis what she may perceive as being situationally acceptable to their interactional audience (interviewer).

In summary, is the mother's narrative credible as an argument? The anxiety she describes as an adult L2 speaker, her a-priori marginalized position as a member of an ethnic minority, and her attempt to resist it in the interactional world may potentially cohere with a sense of moral sympathy and solidarity on the part of at least some of her audience (criterion 10). Taking into account also its inter-diegetic coherence, as argued above (criteria 1, 2, 3), the story seems plausible as something that could have in fact happened (criterion 9) although this is, as Olmos warns, a complex issue in itself and should therefore be approached with caution. Lastly, the actual audience does not explicitly dispute the mother's main thesis, suggesting an alignment with its previous beliefs (criterion 8), notwithstanding certain genre constraints. 


\section{Concluding remarks}

Building on Tindale (2017), I note that rather than operating with definitions that are too strict and that a priori close the semantic field and thus preclude one discursive form from being compatible with another, one should instead look at how particular utterances with narrative-argumentative potential get constructed in a particular discursive context and how the multilayered contextual particulars may signal and discursively index narrators' argumentativenarrative goals. A dynamic view of not only argument but also narrative accommodates such concerns and, as Tindale suggests, invites "a broader range of discourses to qualify" (2017, p. 11).

Relatedly, Tindale's (2017) dynamic view specifically calls for an audience perspective on narrative arguments. In this study, drawing on a concept of a multilayered audience operating across Bamberg's (1997) three positioning levels of discourse that both cohere with and conveniently complement Olmos' criterial framework for assessing story credibility allowed for a contextually relevant analysis of which audience-grounded questions regarding the constructed narrative arguments may arise, where, and when. In so doing, it became apparent that it is crucial to pay attention to potential contextual and situational genre limitations (Carranza 2015) as they affect which critical questions may realistically be asked, by whom, and when. Indeed, unless an interviewer is willing to flout the convention and adopt an interview style where interviewees are actively challenged (see e.g., Bourdieu and Ferguson 1999), the genre of research interviews itself clearly puts limits on the realization of the argumentative potential of narratives constructed therein. The presence of more than one interviewee of equal power status may increase the interactional possibilities and hence aid in unleashing the argumentative potential. Nonetheless, contextual expectations, such as heeding politeness conventions, may still apply and constrain this potential to at least some degree.

Additionally, I note a tension between the situational rhetorical appeal of short conversational stories and keeping a critical distance as an audience and thus assuring that one is not swayed by the drama and vividness of the story itself but rather that one, as an interactional audience, remains on critical guard. This particularly 
concerns the extra-diegetic criteria of credibility, such as our moral judgements (criterion 10) or previous audience beliefs (criterion 8). Regarding the latter, a different interactional audience in the first empirical example may not have expressed any need to challenge the narrator's explanation and its status as potentially anecdotal evidence only.

It is also important to bear in mind that, as Olmos (2015) underscores, the very process of assessing story credibility represents an actual argumentative practice in itself that also has its audience. While this has not been specifically addressed in this paper, it is a position necessarily adopted in the actual analysis and its presentation. Indeed, applying the assessment criteria necessitated normative interpretative decisions regarding the degree of credibility of the constructed story worlds, interactional worlds, and also the highly abstract worlds of circulating macro-discourses voiced by the imagined audience.

Furthermore, in assessing the argumentative potential of narratives, the issue of narrative formats was key. The analysis demonstrated that conversational stories, constructed by just one narrator in a more linear chronological fashion with few interruptions and with much narrative detail (example 1), may be more easily amenable to inter-diegetic assessments of their argumentative potential than more complex stories with multiple narrators. Yet, this does not necessarily imply that they will work as plausible evidence vis-à-vis their multilayered audience. Also, importantly, even in seemingly less structurally complex cases, disambiguating the narrative-argumentative conundrum is far from straightforward. The analyst may be left with several interpretative options, the plausibility of which will depend on how much of the preceding and ensuing discursive context is brought on board and how it is analytically related to the narrative-argumentative activity at hand. Indeed, where does one argument begin and end in conversational discourse of the kind presented here? Corresponding to the notorious difficulty of deciding on narrative boundaries (Riessman 2008), the challenge of shifting argumentative structures is a plausible one in cases where narrative, argumentative, and explanatory modes of discourse may feed into each other in unpredictable ways. 
That these issues can become even more complex was illustrated in the second example. Indeed, more interactive stories with a broader tellership, including several co-narrators and a wider audience, are necessarily more dynamic and fluid. Hence, they are also more structurally challenging to deconstruct as arguments. Through a swift succession of conversational turns and interactional frames, the analyst faces even more urgently the compound challenge of drawing clear boundaries not only between one story and the next but also in terms of what argument is being put forward, how it is being defended, and how it fits in the overall argumentative structure. Such highly dynamic discourse may in fact contain only story snippets or fragments, serving more local claimbacking purposes (Carranza 1999). It may also be replete with multiple interruptions, false starts at formulations of an argument or narration, and unfinished formulations. This then seriously complicates any attempt to assess its narrative-argumentative potential. It also underscores and extends Tindale's (2017) point of critique against the static view, that even if the narrator may have the advantage of hindsight, the audience does not; in fact, given the interactional demands, the narrator may derail from a linear narrative telling in a myriad of ways and thus lose not only hindsight but also sight of their main narrative claim or reasoning.

This then suggests that, from a dynamic view, a rigid application of any criterial framework may not be particularly useful. Instead, contextual relevance should always be addressed and assessed carefully. In fact, echoing Olmos (2015), any attempt at constructing an all-embracing theory of story credibility, one that would take into account the rhetorical aspects of arguments, may be a daunting task indeed. This is not only because of the element of the unexpected in human affairs (Olmos 2015) but simply because of the ever-changing contextual parameters embedded in the dynamic view. Combining insights from argumentation theory and sociolinguistic research within discourse analysis, as attempted here, on how arguers-narrators draw on a wide range of resources to make what they say plausible at a particular point in time, in a specific context, and for specific real and imagined audiences may shed more light on this complex endeavour. 
Acknowledgements: An earlier version of the paper was presented at the 12th OSSA Conference (Windsor, 3-6 June 2020, https://scholar.uwindsor.ca/ossaarchive/OSSA12/Thursday/5/). I would like to thank my OSSA commentator, Paula Olmos, for her constructive commentary and the conference participants for pertinent questions and insights. I am also grateful to Tone Kvernbekk for her support and helpful comments on ideas developed in the paper and the two anonymous reviewers of Informal Logic for their recommendations.

\section{References}

Andersson, Mette. 2012. The debate about multicultural Norway before and after 22 July 2011. Identities 19(4): 418-427. https://doi.org/10.1080/1070289X.2012.684442

Bubikova-Moan, Jarmila. 2017a. Discursive portraits of language, literacy and learning: emerging bilinguals in Norway. [Doctoral Dissertation]. Oslo: University of Oslo.

Bubikova-Moan, Jarmila. 2017b. Negotiating learning in early childhood: narratives from migrant homes. Linguistics and Education 39 (June): 26-36. https://doi.org/10.1016/j.linged.2017.04.003

Bubikova-Moan, Jarmila. 2019. Reported parent-teacher dialogues on child language learning: Voicing agency in interview narratives. International Journal of Bilingual Education and Bilingualism 22 (6): 768-86. https://doi.org/10.1080/13670050.2017.1313192

Bamberg, Michael. 1997. Positioning between structure and performance. Journal of Narrative and Life History 7(1-4): 335-342.

—. 2004. Talk, small stories, and adolescent identities. Human Development. 47(6): 366-69. http://doi.org/10.1159/000081039

Bamberg, Michael and Alexandra Georgakopoulou. 2008. Small stories as a new perspective in narrative and identity analysis. Text \& Talk An Interdisciplinary Journal of Language, Discourse Communication Studies. 28(3): 377-396.

http://www.doi.org/10.1515/TEXT.2008.018

Bennett, W. Lance. 1975. Political Scenarios and the Nature of Politics. Philosophy \& Rhetoric 8(1):23-42.

. 1978. Storytelling in criminal trials: A model of social judgment. Quarterly Journal of Speech. 64(1): 1-22. https://nca.tandfonline.com/doi/abs/10.1080/00335637809383408. 
Billig, Michael. 2016. Whose terms? Whose ordinariness? Rhetoric and ideology in conversation analysis. Discourse \& Society. 10(4): 543558. https://doi.org/10.1080/00335637809383408

Bourdieu, Pierre and Priscilla Parkhurst Ferguson. 1999. The weight of the world: social suffering in contemporary society. Cambridge: Polity Press.

Brochmann, Grete and Anne Britt Djuve. 2013. Multiculturalism or assimilation? The Norwegian welfare state approach. In Debating multiculturalism in the Nordic welfare states, eds. Peter Kivisto and Östen Wahlbeck. Basingstoke: Palgrave Macmillan.

Brochmann, Grete and Anniken Hagelund, eds. 2012. Immigration policy and the Scandinavian welfare state, 1945-2010. Palgrave Macmillan.

Carranza, Isolda E. 1998. Low-narrativity and argumentation. Narrative Inquiry 8(2): 287-317.

- 1999. Winning the battle in private discourse: Rhetoricallogical operations in storytelling. Discourse \& Society 10(4): 509541.

2015. Narrating and arguing. From plausibility to local moves. In Handbook of Narrative Analysis, eds. Anna De Fina and Alexandra Georgakopoulou. Wiley Online Library.

De Fina, Anna. 2003. Identity in narrative: a study of immigrant discourse. Amsterdam/Philadelphia: John Benjamins.

De Fina, Anna and Alexandra Georgakopoulou. 2012. Analyzing narrative: discourse and sociolinguistic perspectives. Cambridge: Cambridge University Press.

Fisher, Walter R. 1984. Narration as a human communication paradigm: the case of public moral argument. Communication Monographs 51(1): 1 .

. 1985. The narrative paradigm: an elaboration. Communication Monographs 52(4): 347.

- 1989. Human communication as narration: toward a philosophy of reason, value and action. Columbia, S.C: University of South Carolina Press.

- 1989. Clarifying the narrative paradigm. Communication Monographs 56(1): 55.

Georgakopoulou, Alexandra. 2007. Small stories, interaction and identities. Amsterdam: John Benjamins.

Govier, Trudy. 2013. Teaching and learning, stories and arguments. Scandinavian Journal of Educational Research 57(6): 1-13. 
Govier, Trudy and Lowell Ayers. 2012. Logic and parables: Do these narratives provide arguments? Informal Logic 32(2): 161-89. https://doi.org/10.22329/il.v32i2.3457

Grosjean, François and Ping Li, eds. 2013. The psycholinguistics of bilingualism. Malden, Mass.: Wiley-Blackwell.

Kvernbekk, Tone. 2003. On the argumentative quality of explanatory narratives. In Anyone who has a view: Theoretical contributions to the study of argumentation, eds. Frans H. Van Eemeren, J. Anthony Blair, Charles A. Willard and A. Francisca Snoeck Henkemans. Dordrecht: Springer.

2013. Narrative configuration: some notes on the workings of hindsight. Scandinavian Journal of Educational Research 57(6): 639-51. https://doi.org/10.1080/00313831.2013.798834.

Labov, William. 1972. Language in the inner city: Studies in the black English vernacular. Philadelphia: University of Pennsylvania Press.

Labov, William and Joshua Waletzky. 1967. Narrative analysis: Oral versions of personal experience. In Essays on the verbal and visual arts, ed. June Helm. Seattle: University of Washington Press.

Ministry of Children and Families. 2012. Meld. St. 6 (2012-2013) Helhetlig integreringspolitikk. [While Paper 6 (2012-2013) A comprehensive integration policy]. URL accessed 10 September 2014: $<$ www.regjeringen.no $>$.

Ministry of Education and Research. 2019. Integrering gjennom kunnskap. Regjeringens integreringsstrategi 2019-2022. [Integration through knowledge. The governmental integration strategy 20192022]. URL accessed 1 September 2020: <www.regjeringen.no>.

Ochs, Elinor and Lisa Capps. 2001. Living narrative: Creating lives in everyday storytelling. Cambridge, MA: Harvard University Press.

Olmos, Paula. 2013. Narration as argument. In Proceedings of the tenth conference of the Ontario Society for the Study of Argumentation, Vol. 10, eds. Dima Mohammed and Marcin Lewinski. Windsor: University of Windsor.

. 2014. Classical fables as arguments: Narration and analogy. In Systematic approaches to argument by analogy, ed. Henrique Jales Ribeiro. Springer.

2015. Story credibility in narrative arguments. In Reflections on theoretical issues in argumentation theory, eds. Frans H. van Eemeren and Bart Garssen. Amsterdam: Springer International Publishing. International Publishing. 2020. Commentary on Jarmila Bubikova-Moan's 'Unpacking the narrative-argumentative conundrum: Story credibility revisited.' 
In Proceedings of the 12th Conference of the Ontario Society for the Study of Argumentation (OSSA). University of Windsor, Canada: OSSA Conference Archive.

$<$ https://scholar.uwindsor.ca/ossaarchive/OSSA12/>.

Plumer, Gilbert. 2011. Novels as arguments. In Proceedings of the 7th conference of the International Society for the Study of Argumentation. Amsterdam: Rozenberg Quarterly http://rozenbergquarterly.com/issa-proceedings-2010-table-ofcontents/

Riessman, Catherine Kohler. 2008. Narrative methods for the human sciences. LA: Sage Publications.

Rowland, Robert C. 1987. Narrative: Mode of discourse or paradigm? Communication Monographs 54(3): 264.

Schegloff, Emanuel A. 1997. Whose text? Whose context? Discourse Society 8(2): 165-87. https://doi.org/10.1177/0957926597008002002

Tindale, Christopher. 2017. Narratives and the concept of argument. In Narration as Argument, Vol. 31, ed. Paula Olmos. Cham: Springer International Publishing.

Tindale, Christopher W. 2015. The philosophy of argument and audience reception. Cambridge University Press.

Warnick, Barbara. 1987. The narrative paradigm: Another story. Quarterly Journal of Speech 73(2): 172.

Wetherell, Margaret. 1998. Positioning and interpretative repertoires: Conversation analysis and post-structuralism in dialogue. Discourse Society 9(3): 387-412. https://doi.org/10.1177/0957926598009003005

Wortham, Stanton and Vivian Gadsden. 2006. Urban fathers positioning themselves through narrative: An approach to narrative selfconstruction. In Discourse and Identity, eds. Anna De Fina, Deborah Schiffrin, and Michael Bamberg. Cambridge: Cambridge University Press.

\section{Appendix 1: Discourse-analytic transcription conventions}

Falling intonation

? Rising intonation

! Animated tone of voice

(.) Micro-pause

«» Direct speech

(a) Laughter

(( )) Transcriber comment/description

- Self- or other-interruption 